\title{
The effect of two cross-linking agents on dentin bond strength of resin-modified glass ionomer
}

\author{
Fereshteh Shafiei ${ }^{1}$, Maryam Firouzmandi², Moona Zamanpour ${ }^{2}$
}

Correspondence: Dr. Maryam Firouzmandi

Email: firouzmandi@sums.ac.ir

\begin{abstract}
'Oral and Dental Disease Research Center, Department of Operative Dentistry, School of Dentistry, Shiraz University of Medical Sciences, Shiraz, Iran, 2Department of Operative Dentistry, School of Dentistry, Shiraz University of Medical Sciences, Shiraz, Iran
\end{abstract}

\section{ABSTRACT}

Objectives: The hybrid layer at the interface of resin-modified glass ionomer cements and dentin is prone to degradation by endogenous matrix metalloproteinases. We aimed to investigate the effect of two types of collagen crosslinkers, carbodiimide and proanthocyanidin (PA), on immediate and medium-term bond strength of a resin-modified glass ionomer to dentin. Materials and Methods: Seventy-two molars were flattened on the occlusal surface to expose dentin. The specimens were divided into control, 1-ethyl-3-(3-dimethylaminopropy) carbodiimide hydrochloride (EDC), and PA groups $(n=24)$. In the EDC and PA groups, carbodiimide and PA solutions were applied for $1 \mathrm{~min}$, respectively. Resin-modified glass ionomer was bonded. Half of the specimens in each group were tested for shear bond strength after $24 \mathrm{~h}$ and the other half were tested after 6 months. Statistical Analysis: Data were analyzed with SPSS version 16 (SPSS Inc, Chicago, IL, USA), using two-way ANOVA, and subgroup analysis was performed using one-way ANOVA, Tukey's test, and $t$-test. Results: Two-way ANOVA showed that treatment and time affected the bond strength. Carbodiimide and PA did not affect the immediate bond strength $(P=0.51)$. After 6 months, the bond strength of the EDC group was significantly lower than that of the control and PA groups. Bond strength of the control and PA groups increased after 6 months $(P \leq 0.002)$. Conclusion: PA did not interfere with maturation of RMGIC unlike carbodiimide. Therefore, it can be suggested as an matrix metalloproteinase inhibitor before bonding of resin-modified glass ionomer to dentin.

Key words: Bond strength, carbodiimide, matrix metalloproteinase, proanthocyanidin, resin-modified glass ionomer

\section{INTRODUCTION}

Resin-modified glass ionomers (RMGIs) are categorized as adhesive restorative materials. ${ }^{[1]}$ Two major mechanisms are involved in adhesion of RMGIs to dental hard structures. The first mechanism is an ionic interaction between carboxylic groups of polyacrylic acid (PAA) and the calcium present in the enamel and dentin. ${ }^{[1]}$ The second mechanism is induced by monomers present in their composition. A hybrid-like layer is formed by penetration of resin monomers in conditioned dentin. ${ }^{[2]}$ PAA was

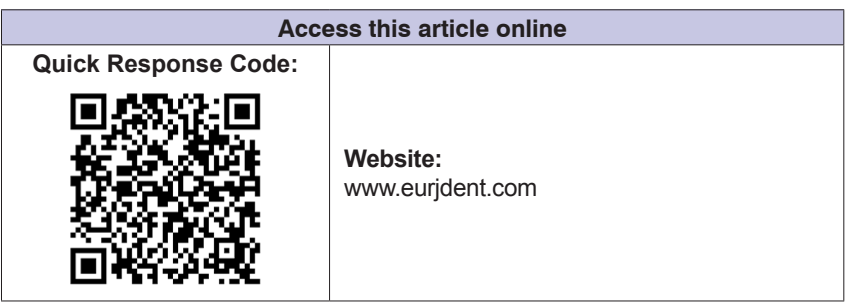

suggested as a dentin conditioner before bonding with RMGIs. ${ }^{[3,4]}$ This conditioning step removes the smear layer and exposes the collagen fibrils up to approximately $0.5-1 \mu \mathrm{m}$ in depth. ${ }^{[5]}$ The $\mathrm{pH}$ of this conditioner is about 1.90 (ftp://ftp.endoco.com/ MSDS/GCCavityConditioner.pdf). Some collagen fibrils at the base of the hybrid layer may remain unprotected when PAA conditioner is used before RMGI restoration. ${ }^{[6]}$ It has been shown that degradation of the adhesive joint begins by hydrolysis of denuded

This is an open access article distributed under the terms of the Creative Commons Attribution-NonCommercial-ShareAlike 3.0 License, which allows others to remix, tweak, and build upon the work non-commercially, as long as the author is credited and the new creations are licensed under the identical terms.

For reprints contact: reprints@medknow.com

How to cite this article: Shafiei F, Firouzmandi M, Zamanpour M. The effect of two cross-linking agents on dentin bond strength of resinmodified glass ionomer. Eur J Dent 2017;11:486-90.

DOI: 10.4103/ejd.ejd_258_17 
collagen fibrils by some endogenous proteolytic enzymes. ${ }^{[7]}$ Matrix metalloproteinases (MMPs) and cysteine cathepsins are major proteases of this category. ${ }^{[8]}$ Caries, acid-etching of dentin, and even mildly acidic components in adhesive resins transform the inactive form of MMPs to active proteases..$^{[9,10]}$ 1-ethyl-3[3-dimethylaminopropy] carbodiimide hydrochloride (carbodiimide) and proanthocyanidin (PA) are both cross-linking agents and MMP inhibitors. ${ }^{[11,12]}$ Carbodiimide is a synthetic chemical compound and PA is available in several natural extracts such as grape seed extract. Both these agents increased the bond stability of adhesive resins to dentin without compromising immediate bond strength. ${ }^{[13-15]}$ The effect of chlorhexidine and ethylenediaminetetraacetic acid (EDTA) as an MMP inhibitor on the resistance of RMGIC-dentin bond to degradation has been studied. ${ }^{[5,6]}$ Chlorhexidine failed to increase the long-term stability of the bond, ${ }^{[5]}$ but EDTA could avoid a decrease in bond strength after 3 months of storage. ${ }^{[6]}$ The aim of the present study was to test the following null hypotheses: (1) carbodiimide and PA do not affect the shear bond strength (SBS) of RMGI after $24 \mathrm{~h}$ and 6 months and (2) there is no difference between 24-h and 6-month SBS in the study groups.

\section{MATERIALS AND METHODS}

Seventy-two noncarious human molars were used in this in vitro study. The teeth were extracted for surgical or periodontal reasons and kept in $0.5 \%$ chloramine $\mathrm{T}$ solution at $4^{\circ} \mathrm{C}$ until used for the purpose of the study. ${ }^{[16]}$ The study protocol was approved by the Ethics Committee of the university.

The teeth were mounted in self-curing acrylic resin (RE Acropars, Marlic Medical Industries Co., Tehran, Iran). The occlusal enamel of the teeth was grounded with 800-grit sandpaper mounted on a polishing machine (Planopol 3, Struers, Kobenhavn, Denmark) under water cooling. The exposed flat dentin surfaces were examined under $\times 40$ to ensure complete removal of the occlusal enamel. Dentin surfaces of the specimens were conditioned with $10 \%$ PAA (Cavity Conditioner, GC Corporation, Tokyo, Japan, \#1402261) for $20 \mathrm{~s}$, rinsed, and dried to maintain a moist surface. The specimens were randomly divided into control, 1-ethyl-3-(3-dimethylaminopropy) carbodiimide hydrochloride (EDC), and PA groups $(n=24)$.

After conditioning, no treatment was used in the control group. In the EDC group, the specimens were treated with $0.3 \mathrm{M}$ water-soluble 1-ethyl-3[3-dimethylaminopropyl] carbodiimide hydrochloride (Sigma-Aldrich, St. Louis, MO, USA, \#MKBP2831V) for 1 min and gently air-dried. ${ }^{[17]}$ In the PA group, $6.5 \%$ grape seed extract solution was applied on the specimens for $1 \mathrm{~min}$ followed by a gentle air stream. ${ }^{[17]}$ The solution was prepared using $6.5 \mathrm{gr}$ of grape seed extract in the form of powder (Puritans Pride Inc., Oakdale, NY, USA, \#768890-02), dissolved in $100 \mathrm{~mL}$ of distilled water. ${ }^{[18]}$ Then, RMGI (Fuji II LC, GC Corporation, Tokyo, Japan, \#1310171) was mixed according to the manufacturer's instructions and packed into cylindrical plastic molds $($ diameter $=2.4 \mathrm{~mm}$, height $=2 \mathrm{~mm}$ ), which were placed on the cut surface of the tooth and light-cured (Coltolux 75, Whaledent Inc., Coltene, USA) at an intensity of $600 \mathrm{~mW} / \mathrm{cm}^{2}$ for $30 \mathrm{~s}$. Then, the specimens in each group were divided into two subgroups $(n=12)$. The sample size was determined based on similar bond strength studies regarding crosslinkers and RMGI. ${ }^{[3,18,19]}$ Half of the specimens were stored in distilled water at $37^{\circ} \mathrm{C}$ for $24 \mathrm{~h}$ in an incubator, and then the SBS was measured. The other half were stored in distilled water at $37^{\circ} \mathrm{C}$ for 6 months in the incubator before SBS test.

The test was conducted with a universal testing machine (Zwick-Roell, Zwick, Ulm, Germany) at a cross-head speed of $0.5 \mathrm{~mm} / \mathrm{min} \cdot{ }^{[20,21]}$ The debonded specimens were observed under a stereomicroscope (Carl Ziess Inc., Oberkochen, Germany) at $\times 40$. Fracture modes of the specimens were classified as follows: A: adhesive, C: cohesive failure in RMGI, and M: mixed failure. ${ }^{[5]}$ The effects of treatment and storage time factors and their interaction were statistically analyzed with two-way ANOVA. One-way ANOVA and Tukey's tests were used to compare the effect of different treatments on SBS at each time interval. Paired-sample $t$-test was used to compare SBS of each treatment group after $24 \mathrm{~h}$ and 6 months.

\section{RESULTS}

Means and standard deviations of SBS in the control and study groups after $24 \mathrm{~h}\left(\mathrm{~T}_{0}\right)$ and 6 months $\left(\mathrm{T}_{6}\right)$ of storage are reported in Table 1 . Treatment and time affected SBS. There was a statistically significant interaction between the two factors $(P<0.001)$. For each time interval, one-way ANOVA revealed that: (1) carbodiimide and PAs did not affect the immediate SBS of RMGI to dentin $(P=0.51)$; (2) SBS of the EDC group was lower than that of the control and PA groups at $\mathrm{T}_{6}(P<0.001)$. SBS of the PA group was 


\begin{tabular}{|c|c|c|c|}
\hline \multirow{3}{*}{ Groups } & \multirow{2}{*}{\multicolumn{2}{|c|}{$\begin{array}{c}\text { Mean (SD)* } \\
\text { Failure A/C/M }\end{array}$}} & \multirow{3}{*}{$P\left(\mathrm{~T}_{0}\right.$ vs. $\left.\mathrm{T}_{6}\right)$} \\
\hline & & & \\
\hline & $\mathrm{T}_{0}$ & $\mathrm{~T}_{6}$ & \\
\hline Control & $\begin{array}{c}6.90(2.19)^{\mathrm{a}, \mathrm{A}} \\
5 / 4 / 3\end{array}$ & $\begin{array}{c}13.36(4.76)^{a, b} \\
4 / 2 / 6\end{array}$ & 0.002 \\
\hline EDC & $\begin{array}{c}6.27(1.97)^{\mathrm{a}, \mathrm{A}} \\
5 / 3 / 4\end{array}$ & $\begin{array}{c}4.64(1.69)^{\mathrm{b}, \mathrm{A}} \\
8 / 2 / 2\end{array}$ & 0.06 \\
\hline PA & $\begin{array}{c}7.39(2.23)^{\mathrm{a}, \mathrm{A}} \\
5 / 2 / 5\end{array}$ & $\begin{array}{c}14.41(2.54)^{\mathrm{a}, \mathrm{B}} \\
2 / 2 / 8\end{array}$ & $<0.001$ \\
\hline$P$ & 0.51 & $<0.001$ & \\
\hline \multicolumn{4}{|c|}{$\begin{array}{l}\text { *The same lowercase letters indicate no statistically significant } \\
\text { difference within each column for each time interval (differently } \\
\text { treated groups, according to one-way ANOVA with } P \text { value and } \\
\text { Tukey tests). The same uppercase letters indicate no statistically } \\
\text { significant difference within each row ( } T_{0} \text { vs. } T_{6} \text { according to } t \text {-test } \\
\text { with } P \text { value) }(P>0.05) \text {. EDC: } 1 \text {-ethyl-3-(3-dimethylaminopropy) } \\
\text { carbodiimide hydrochloride, PA: Proanthocyanidin, } \\
\text { A/C/M: Adhesive, cohesive, mixed, SD: Standard deviation }\end{array}$} \\
\hline
\end{tabular}

not significantly different from that of the control at $\mathrm{T}_{6}(P=0.75)$ (Tukey's multiple comparisons) [Table 1]. According to $t$-test, there was a significant increase in the bond strength of the control and PA groups after 6 months $(P \leq 0.002)$. In contrast, the EDC group exhibited a statistically insignificant reduction in bond strength $(P=0.06)$ [Table 1]. The results of the failure modes in the six study groups are presented in Table 1. There was no difference in fracture modes of the study groups at $\mathrm{T}_{0}$ but after 6 months the groups showed different fracture patterns. Control and PA groups showed a high percentage of mixed failures, but the most prevalent failure mode in the EDC group was adhesive.

\section{DISCUSSION}

Carbodiimideand PA were used as collagen crosslinkers and MMP inhibitors to increase degradation resistance of bonding interface of the RMGIC and dentin in the present study. Although these agents had no effect on immediate SBS, carbodiimide hindered maturation and improvement of bond strength after 6 months compared to the control and PA groups. Therefore, the first null hypothesis was partly accepted. Triple helix spatial structure of the dentin collagen resists proteolytic degradation. ${ }^{[14]}$ Binding of MMPs and cysteine cathepsins ${ }^{[8]}$ results in the unwinding of dentin collagen helical structure. ${ }^{[14]}$ Crosslinkers stiffen the collagen so that it cannot unwind. ${ }^{[14]}$ Furthermore, they can cross-link proteinases and directly interfere with their function. ${ }^{[14]}$ However, carbodiimide and PAs differ in their mechanism of interaction with proteins. This might account for their different effects on the 6-month bond strength of RMGI. PA has a high affinity for proline-rich proteins like collagen forming a proline-PA complex. ${ }^{[22]}$ There is controversy on the interaction mechanism of PA with collagen. Four different mechanisms are proposed: covalent interaction, ionic interaction, hydrogen bonding, or hydrophobic interactions. ${ }^{[15]}$

Carbodiimide has a unique capacity to activate carboxylic groups of glutamic and aspartic acids to form $\mathrm{O}$-acylisourea. The reaction of this intermediate product with $\varepsilon$-amino groups of lysine and hydroxylysine results in the formation of an amide cross-link and urea. ${ }^{[23]}$

Increased bond strength with time was observed in the control group. This was consistent with the results of previous studies. Improvement of the bond strength was attributed to maturation of RMGI. ${ }^{[3,5]}$ Acid-base reaction is a known setting mechanism for GICs. This response is retarded in RMGIs by the lack of water and presence of HEMA in their formula. ${ }^{[3,24]}$ The acid-base reaction begins when carboxylic groups of PAA attacks fluoroaluminosilicate glass particles. Continuous and slow diffusion of the ions from the tooth to the interdiffusion zone leads to the maturation and strengthening of the bond..$^{[3]}$ This might be responsible for increased SBS of the control group. This significant increase was also observed for PA group. Bond strengths of the PA group at $T_{0}$ and $\mathrm{T}_{6}$ were higher than those in the control group, but the difference was insignificant. PA does not hinder the resin infiltration; therefore, the micromechanical retention of RMGI might not undergo any changes. The interaction target of PA is collagen which is a molecule rich in proline. ${ }^{[22]} \mathrm{Hydrogen}$ bonding occurs between the protein amide carbonyl group of collagen and the phenolic hydroxyl group of the crosslinker. ${ }^{[11]}$ Thus, the active groups participating in the acid-base reaction of RMGI might not be interrupted.

According to the results of the present study, the bond strength of the EDC group was not different from that of the control group after $24 \mathrm{~h}$, but significantly lower bond strength was recorded for the EDC group after 6 months. Therefore, the second null hypothesis was partly rejected. It seems that carbodiimide might interfere with the maturation process of RMGI. It is supposed that carbodiimide has no detrimental effect on the formation of micromechanical retention,,$^{[13,14]}$ but it may interfere with chemical adhesion of RMGIC, which has been demonstrated to be the main bonding 
mechanism of RMGIC to the dentin. ${ }^{[25]}$ Carbodiimide could hinder the interaction of PAA with the calcium and phosphate ions of the dentin because of its potential to convert negatively charged carboxyl groups to positively charged amide groups. ${ }^{[14]}$ As mentioned earlier, the chemical reaction in RMGIC is retarded, and the rate of the acid-base reaction is reduced. ${ }^{[26]}$ Therefore, during the first $24 \mathrm{~h}$, sufficient active carboxyl groups might be available to complete the slow rate of acid-base reaction in both the control and EDC groups. However, in the EDC group, inadequacy of active carboxyl groups during maturation phase of RMGI may impede improvement of the bond.

The results of SBS were consistent with the observed failure modes. As with SBS, failure modes were similar between groups after $24 \mathrm{~h}$. With completion of the maturation in 6 months, bond strength in the control and PA groups increased and a trend of increased mixed failures could also be recorded. However, adhesive failure was dominant in the EDC group after 6 months because of the impediment of maturation.

The presence of the hybrid layer and resin tags has been documented at the RMGIC-tooth interface, and the possibility of degradation of this layer by endogenous MMPs has been suggested ${ }^{[5,6]}$ It has been reported that the degradation of hybrid layer occurs in both collagen and resin. ${ }^{[13]}$ The amount of the resin component in the composition of RMGIC is low ${ }^{[27]}$ and PAA conditioner exposes less collagen than phosphoric acid. ${ }^{[28]}$ Superimposition of chemical adhesion with micromechanical retention may be beneficial to the long-term stability of this hybrid layer. ${ }^{[5]}$

The aging period was 6 months in the present study, and the control group exhibited higher bond strength after aging because of maturation of the bond. This result was consistent with previous studies. ${ }^{[3,5]}$ This preliminary study revealed the potential interference of each crosslinker with the maturation of RMGI bond; longer periods of aging might be needed to investigate the effect of MMPs on degradation of RMGI-dentin bond layer.

\section{Acknowledgment}

This project (Grant \#9240) was carried out by the financial support from the Deputy Dean of Research at Shiraz University of Medical Sciences. The authors thank Dr. Mehrdad Vosoughi for statistical analysis of the data and Dr. N. Shokrpour at center for Development of Clinical Research of Nemazee Hospital for editing the English manuscript.

\section{CONCLUSION}

Within the limitations of the current study, it can be concluded that PA did not interfere with maturation of RMGIC unlike Carbodiimide. Therefore, PA can be used as matrix metalloproteinase inhibitor before bonding of RMGIC to dentin

\section{Financial support and sponsorship \\ Nil.}

\section{Conflicts of interest}

There are no conflicts of interest.

\section{REFERENCES}

1. Yoshida Y, Van Meerbeek B, Nakayama Y, Snauwaert J, Hellemans L, Lambrechts $\mathrm{P}$, et al. Evidence of chemical bonding at biomaterial-hard tissue interfaces. J Dent Res 2000;79:709-14.

2. Inoue S, Abe Y, Yoshida Y, De Munck J, Sano H, Suzuki K, et al. Effect of conditioner on bond strength of glass-ionomer adhesive to dentin/enamel with and without smear layer interposition. Oper Dent 2004;29:685-92

3. Yap AU, Tan AC, Goh AT, Goh DC, Chin KC. Effect of surface treatment and cement maturation on the bond strength of resin-modified glass ionomers to dentin. Oper Dent 2003;28:728-33.

4. El-Askary FS, Nassif MS. The effect of the pre-conditioning step on the shear bond strength of nano-filled resin-modified glass-ionomer to dentin. Eur J Dent 2011;5:150-6.

5. Dursun E, Le Goff S, Ruse DN, Attal JP. Effect of chlorhexidine application on the long-term shear bond strength to dentin of a resin-modified glass ionomer. Oper Dent 2013;38:275-81.

6. Fagundes TC, Toledano M, Navarro MF, Osorio R. Resistance to degradation of resin-modified glass-ionomer cements dentine bonds. J Dent 2009;37:342-7.

7. Hashimoto $\mathrm{M}$, Ohno $\mathrm{H}$, Sano H, Kaga M, Oguchi H. In vitro degradation of resin-dentin bonds analyzed by microtensile bond test, scanning and transmission electron microscopy. Biomaterials 2003;24:3795-803.

8. Hiraishi N, Sono R, Sofiqul I, Yiu C, Nakamura H, Otsuki M, et al. In vitro evaluation of plant-derived agents to preserve dentin collagen. Dent Mater 2013;29:1048-54.

9. Nishitani Y, Yoshiyama M, Wadgaonkar B, Breschi L, Mannello F, Mazzoni A, et al. Activation of gelatinolytic/collagenolytic activity in dentin by self-etching adhesives. Eur J Oral Sci 2006;114:160-6.

10. Tay FR, Pashley DH, Loushine RJ, Weller RN, Monticelli F, Osorio R, et al. Self-etching adhesives increase collagenolytic activity in radicular dentin. J Endod 2006;32:862-8.

11. Hass V, Luque-Martinez IV, Gutierrez MF, Moreira CG, Gotti VB, Feitosa VP, et al. Collagen cross-linkers on dentin bonding: Stability of the adhesive interfaces, degree of conversion of the adhesive, cytotoxicity and in situ MMP inhibition. Dent Mater 2016;32:732-41.

12. Mazzoni A, Apolonio FM, Saboia VP, Santi S, Angeloni V, Checchi V et al. Carbodiimide inactivation of MMPs and effect on dentin bonding. J Dent Res 2014;93:263-8.

13. Bedran-Russo AK, Vidal CM, Dos Santos PH, Castellan CS. Long-term effect of carbodiimide on dentin matrix and resin-dentin bonds. J Biomed Mater Res B Appl Biomater 2010;94:250-5.

14. Mazzoni A, Angeloni V, Apolonio FM, Scotti N, Tjäderhane L, Tezvergil-Mutluay A, et al. Effect of carbodiimide (EDC) on the bond stability of etch-and-rinse adhesive systems. Dent Mater 2013;29:1040-7.

15. Al-Ammar A, Drummond JL, Bedran-Russo AK. The use of collagen cross-linking agents to enhance dentin bond strength. J Biomed Mater Res B Appl Biomater 2009;91:419-24.

16. Shafiei F, Yousefipour B, Mohammadi-Bassir M. Effect of carbodiimide on bonding durability of adhesive-cemented fiber posts in root canals. Oper Dent 2016;41:432-40. 
17. Scheffel DL, Hebling J, Scheffel RH, Agee K, Turco G, de Souza Costa CA, et al. Inactivation of matrix-bound matrix metalloproteinases by cross-linking agents in acid-etched dentin. Oper Dent 2014;39:152-8.

18. Srinivasulu S, Vidhya S, Sujatha M, Mahalaxmi S. Shear bond strength of composite to deep dentin after treatment with two different collagen cross-linking agents at varying time intervals. Oper Dent 2012;37:485-91.

19. Altunsoy M, Botsali MS, Korkut E, Kucukyilmaz E, Sener Y. Effect of different surface treatments on the shear and microtensile bond strength of resin-modified glass ionomer cement to dentin. Acta Odontol Scand 2014;72:874-9.

20. Doozandeh M, Firouzmandi M, Mirmohammadi M. The simultaneous effect of extended etching time and casein phosphopeptide-amorphous calcium phosphate containing paste application on shear bond strength of etch-and-rinse adhesive to caries-affected dentin. J Contemp Dent Pract 2015;16:794-9.

21 Shafiei F, Memarpour M. Effect of repeated use on dentin bond strength of two adhesive systems: All-in-one and one-bottle. Indian J Dent Res 2009;20:180-4
22. Han B, Jaurequi J, Tang BW, Nimni ME. Proanthocyanidin: A natural crosslinking reagent for stabilizing collagen matrices. J Biomed Mater Res A 2003;65:118-24.

23. Tezvergil-Mutluay A, Mutluay MM, Agee KA, Seseogullari-Dirihan R, Hoshika T, Cadenaro M, et al. Carbodiimide cross-linking inactivates soluble and matrix-bound MMPs, in vitro. J Dent Res 2012;91:192-6.

24. Beriat NC, Nalbant D. Water absorption and HEMA release of resin-modified glass-ionomers. Eur J Dent 2009;3:267-72.

25. Cardoso MV, Delmé KI, Mine A, Neves Ade A, Coutinho E, De Moor RJ, et al. Towards a better understanding of the adhesion mechanism of resin-modified glass-ionomers by bonding to differently prepared dentin. J Dent 2010;38:921-9.

26. Wan AC, Yap AU, Hastings GW. Acid-base complex reactions in resin-modified and conventional glass ionomer cements. J Biomed Mater Res 1999;48:700-4.

27. Mount GJ. Glass ionomers: A review of their current status. Oper Dent 1999:24:115-24.

28. Hashimoto M, Ohno H, Sano H, Tay FR, Kaga M, Kudou Y, et al. Micromorphological changes in resin-dentin bonds after 1 year of water storage. J Biomed Mater Res 2002;63:306-11. 